\title{
Conflicto y decapitación humana en Amato (valle de Acarí, Perú)
}

Conflit et décapitation humaine sur le site de Amato (vallée de Acari, Pérou)

Conflict and human decapitation at Amato (Acari Valley, Peru)

\section{Lidio Valdez}

\section{(2) OpenEdition}

\section{Journals}

Edición electrónica

URL: http://journals.openedition.org/bifea/2666

DOI: $10.4000 /$ bifea.2666

ISSN: 2076-5827

\section{Editor}

Institut Français d'Études Andines

\section{Edición impresa}

Fecha de publicación: 1 agosto 2009

Paginación: 177-204

ISSN: 0303-7495

\section{Referencia electrónica}

Lidio Valdez, « Conflicto y decapitación humana en Amato (valle de Acarí, Perú) », Bulletin de l'Institut français d'études andines [En línea], 38 (2) | 2009, Publicado el 01 febrero 2010, consultado el 18 noviembre 2020. URL : http://journals.openedition.org/bifea/2666 ; DOI : https://doi.org/10.4000/ bifea.2666

\section{(9) $\odot \Theta \Theta$}

Les contenus du Bulletin de l'Institut français d'études andines sont mis à disposition selon les termes de la licence Creative Commons Attribution - Pas d'Utilisation Commerciale - Pas de Modification 4.0 International. 


\title{
Conflicto y decapitación humana en Amato (valle de Acarí, Perú)
}

\author{
Lidio Valdez*
}

\section{Resumen}

En este artículo se presentan los resultados de las recientes excavaciones efectuadas en Amato, un sitio ocupado durante las fases iniciales del periodo Intermedio Temprano (ca. 1-350 d.C.), en el valle de Acarí de la costa sur del Perú. Dichos trabajos condujeron al hallazgo de varias decenas de esqueletos humanos (algunos estaban parcialmente momificados) que muestran, como rasgo principal, signos indiscutibles de haber sido decapitados. Además de la ausencia de cráneos, los huesos cervicales presentan varios cortes, lo que indica que los individuos fueron decapitados. Los restos incluyen individuos de todas las edades y de ambos géneros. En varios casos, cuerdas aún atadas fueron halladas alrededor de la parte distal de los huesos radio y cúbito, así como de la tibia y el peroné, lo que señalaría que los decapitados fueron antes tratados como prisioneros. Finalmente, las evidencias adicionales que se discuten en este artículo sugieren que las primeras fases de este periodo fueron relativamente violentas en este valle, situación que obligó al establecimiento de asentamientos con sistemas defensivos.

Palabras clave: Acarí, costa sur, periodo Intermedio Temprano, decapitación humana

\section{Conflit et décapitation humaine sur le site de Amato (vallée de Acari, Pérou)}

\section{Résumé}

Cet article présente les résultats des fouilles récemment éffectuées à Amato, un site établi au début de la Période Intermédiaire Ancien (env. 1-350 après J.-C.) dans la vallée d'Acari sur la côte sud du Pérou. Plusieurs dizaines de squelettes humains y furent découverts, dont certains étaient partiellement momifiés et présentaient des signes indiscutables de décapitation. En plus de l'absence de crânes, 
les vertèbres cervicales supérieures montraient des entailles mettant en évidence une décapitation. Les restes humains correspondent à des individus de tous âges et des deux sexes dont certains avaient encore des cordes autour des poignets et des chevilles, suggérant qu'ils furent traités comme prisonniers. D'autres éléments apportés dans cet article démontrent que les phases primitives de la Période Intermédiaire Ancien furent violentes ce qui conduisit à l'installation de sites pourvus de systèmes défensifs.

Mots clés : Acari, côte sud, période Intermédiare Ancien, décapitation humaine

\title{
Conflict and human decapitation at Amato (Acari Valley, Peru)
}

\begin{abstract}
In this article I present the results of the recent archaeological excavations carried out at Amato, a site established during the early phases of the Early Intermediate Period (ca. AD 1-350) in the Acari Valley, of the south coast of Peru. The findings consist of several dozen human skeletons, some of which are partially mummified. The main feature of the collection is that the skeletons present unmistakable signs of decapitation. In addition to the absence of the skulls, the upper cervical vertebra present cut marks indicating decapitation. The human remains include individuals of all ages and both sexes. Many of the remains were uncovered with ropes around their wrists and ankles, suggesting that they were treated as captives before their decapitation. Finally, additional information is discussed in this paper in order to argue that the early phases of the Early Intermediate Period were violent. Due to such stress, settlements established in the valley at this time were provided with defensive systems.
\end{abstract}

Key words: Acari, south coast, Early Intermediate period, human decapitation

\section{INTRODUCCIÓN}

La decapitación humana —el acto de separar físicamente la cabeza del resto del cuerpo- es una práctica antigua que fue realizada por muchas culturas alrededor del mundo (Chacón \& Dye, 2007). Ello se hace evidente en los relatos bíblicos: por ejemplo, David logra decapitar a Goliat y hasta el mismo Juan Bautista termina siendo decapitado. El oeste sudamericano no fue ajeno a prácticas similares, pues existen evidencias arqueológicas que indican que los antiguos habitantes de esta región también participaron de dicho ritual. Para el caso específico de los Andes Centrales, los rastros más antiguos corresponden al periodo Precerámico (Browne et al., 1993; Proulx, 1971; 1989). En el valle de Acarí, las evidencias más tempranas se ubicaron en el sitio de Hacha del periodo Inicial (ca. 800 a.C.), donde se halló un grupo de tres cabezas humanas que, quizás, son el resultado de decapitaciones.

En los Andes Centrales — por razones que aún son motivo de análisis científico-, la práctica de la decapitación humana fue más prolífera en la costa sur del Perú, en particular durante el periodo Intermedio Temprano (ca. 1-650 d.C.). 
Efectivamente, el arte antiguo de esta región ilustra continuamente las llamadas cabezas trofeo (Proulx, 1971: 18-19; 1989: 73; 2001: 121-122; Sawyer, 1961: 278). Por su parte, la investigación arqueológica ha puesto al descubierto la presencia física de cabezas humanas que son consideradas pruebas de la práctica de la decapitación1 (Baraybar, 1987; Carmichael, 1994; Conlee, 2007; Drusini \& Baraybar, 1991; De Leonardis, 2000; Proulx, 1971; 2001; Silverman, 1988; Silverman \& Proulx, 2002; Verano, 1995; Forgey \& Williams, 2003).

Las cabezas fueron descubiertas por primera vez a inicios del siglo pasado por Max Uhle (Silverman \& Proulx, 2002), quien infirió que estas fueron obtenidas en la guerra. De este modo, Uhle optó por identificarlos como «trofeos» de guerra (Browne et al., 1993). Desde entonces, cabezas trofeo han sido recuperadas de casi todos los valles de la costa sur, incluido el valle de Acarí (Baraybar, 1987; Coehlo, 1972; Neira Avendaño \& Coehlo, 1972-1973; Lothrop \& Mahler, 1957). Estos hallazgos se producen, generalmente, de manera aislada (Silverman, 1988; Forgey \& Williams, 2003; 2005) o en grupos (Kowta, 1987; Neira Avendaño \& Coelho, 1972-1973); aunque una vez se recuperaron 48 cabezas en total (Browne et al., 1993; Verano, 1995). Patrick Carmichael (1988: 183; 1994: 84) sostiene que entre el 5 y el 10 \% de la población Nasca habría terminado como cabeza trofeo.

Una cabeza trofeo, siguiendo la definición de Silverman \& Proulx (2002: 229) y Verano (2003: 526), presenta las siguientes características: ausencia total o parcial del hueso occipital y un orificio en el hueso frontal (en los más conservados se puede apreciar una cuerda incrustada a dicho orificio). En las que aún mantienen la piel, se pueden notar diversos cortes en el cuero cabelludo, así como los labios y los ojos cerrados con espinas (Proulx, 1971). En consecuencia, de acuerdo a esta definición, no toda cabeza separada del resto del cuerpo puede ser identificada como «cabeza trofeo». Del mismo modo, existe la posibilidad que no toda cabeza trofeo puede ser reconocida como producto de la decapitación.

En contraste con la presencia física de las cabezas, la investigación arqueológica a lo largo de toda la costa sur del Perú ha tenido poco éxito en ubicar restos humanos con claros signos de haber sido decapitados (Kroeber, 1956: 325; Doering, 1966 [citado por Browne et al., 1993: 288]; De Leonardis, 2000: 373; Conlee, 2007:440-441). Además, los pocos hallazgos incluyen, por lo general, un solo cuerpo. Tal como se discute más adelante, el tratamiento de los cuerpos decapitados es variable y sugiere que la decapitación humana se llevó a cabo en diversos contextos y por varias razones. Es decir, a contracorriente con la inicial sugerencia de Uhle, la guerra no parece haber sido el único origen de las cabezas. Complicando aún más la poca ocurrencia de cuerpos decapitados, en un caso se ha determinado que la cabeza de un individuo, enterrado previamente, había sido removida (Carmichael, 1988:291). Del mismo modo, el entierro sin cabeza

1 Sin embargo, no está del todo comprobado si estas cabezas y las otras referidas en este artículo fueron obtenidas mediante la decapitación. Lo mismo se puede sostener para las supuestas cabezas trofeo provenientes del sitio Huarpa de Ñawinpukyo (Finucane, 2007): ¿son resultado de la decapitación o son las cabezas de individuos que fallecieron mucho tiempo antes? 
excavado por De Leonardis (2000: 369) no presenta huellas de cortes y deja abierta la posibilidad de que la muerte de dicho individuo no guarde ninguna relación con la decapitación. De acuerdo a Verano (2001: 168), los cortes en los huesos cervicales son indicadores de decapitación. En cambio, el entierro excavado por Conlee (2007: 441) sí presenta huellas de corte en los huesos cervicales.

De esta breve introducción destacamos que la decapitación humana fue relativamente común en la costa sur peruana, a pesar de que los cuerpos con signos indiscutibles de haber sido decapitados siguen siendo poco frecuentes en los contextos arqueológicos. Recientes excavaciones arqueológicas efectuadas en el sitio de Amato —establecido en el valle de Acarí (fig. 1) a inicios del periodo Intermedio Temprano (ca 50 a.C.-350 d.C.) - llevaron al hallazgo de varias decenas de cuerpos humanos con claros signos de decapitación (Valdez, 2005a; 2006; Valdez et al., 2006). Descubrimientos similares nunca han sido encontrados en toda la costa sur o en los Andes Centrales, por ello los hallazgos de Amato son únicos y constituyen la mejor evidencia arqueológica con respecto a la decapitación humana para toda la costa sur. Al mismo tiempo, ofrece una oportunidad sui generis para conocer aspectos relacionados al acto de la decapitación.

Para poner en perspectiva el tema, primero hacemos una breve referencia al sitio de Amato y a las excavaciones donde se encontraron los cuerpos. Luego se describen los hallazgos que constituyen el tema central de este artículo. Para entender mejor el significado de la decapitación, tomamos en consideración datos adicionales, de igual importancia, como los patrones de asentamiento y el diseño de los asentamientos que existieron en Acarí en tiempos del sitio de Amato. Finalmente, este conjunto de evidencias es discutido considerando el carácter geográfico del valle de Acarí.

\section{EL SITIO ARQUEOLÓGICO DE AMATO}

Amato, ubicado en la parte superior media del valle de Acarí (fig. 1), es uno de los sitios arqueológicos mejor conservado de todo el valle (Valdez, 2000; 2006). El sitio fue inicialmente visitado por Rowe (1963) y Menzel \& Riddell (1986). Rowe, en particular, fue el pionero en determinar la ubicación temporal del sitio en las primeras fases del periodo Intermedio Temprano (Valdez, 1998; 2000). Al mismo tiempo, Rowe (1963) observó el muro perimétrico de Amato (fig. 2) y de otros sitios contemporáneos y sugirió que tales construcciones, tal vez, cumplieron funciones defensivas (Valdez, 2006: 4). Al interior del muro perimétrico de Amato existen muchas otras construcciones, de las cuales destaca un recinto cuadrangular ubicado precisamente en la parte central del sitio. Dicho recinto, encierra a su vez otro aún más pequeño pero de forma rectangular (Valdez, 2006: 5). Los hallazgos discutidos en este trabajo provienen del interior de esta última estructura, donde no existen otras estructuras adicionales, excepto un alineamiento de adobes cónicos expuesto en la esquina suroeste del mismo. 


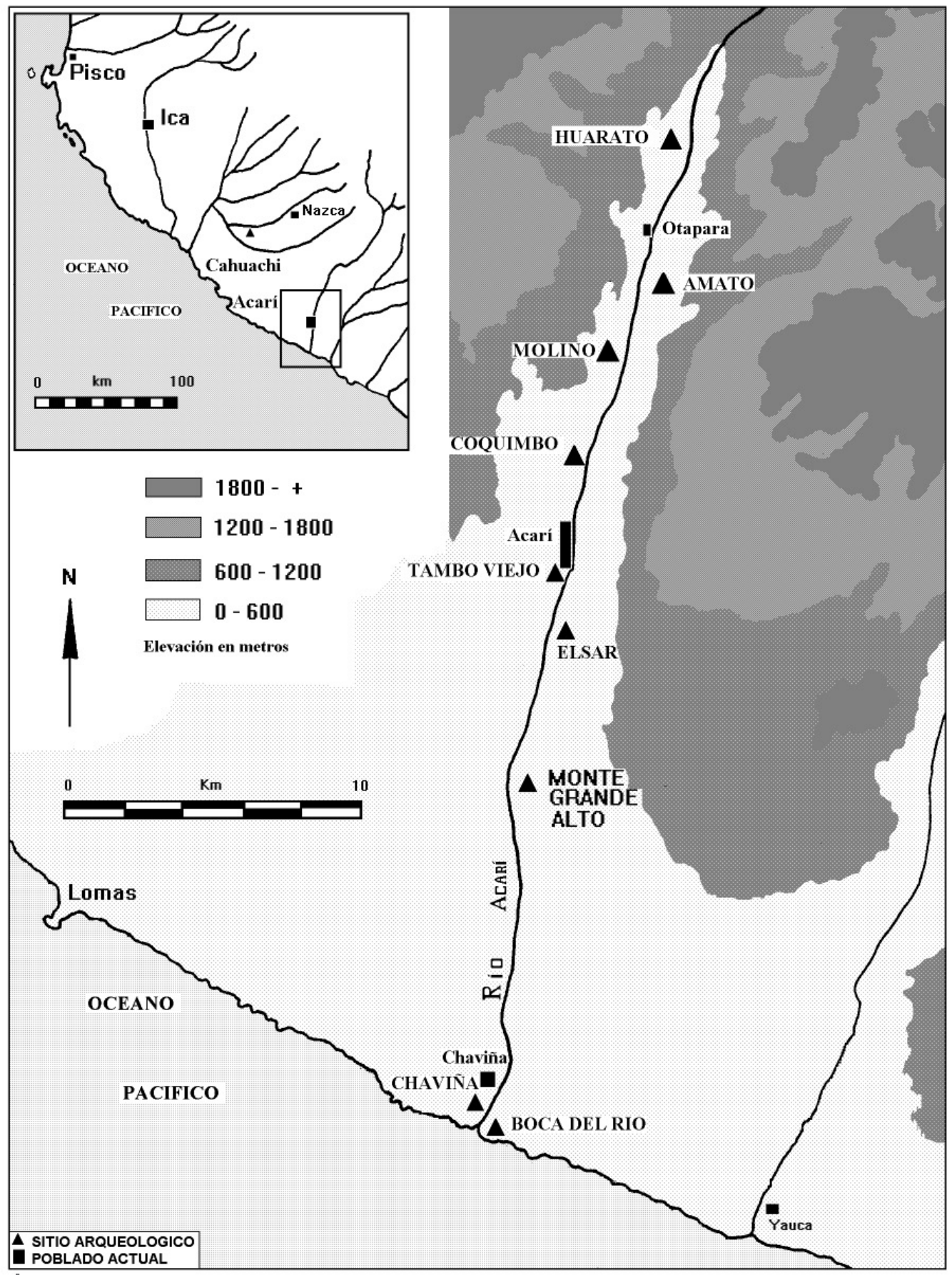

Figura 1 - Ubicación de Amato y otros asentamientos del periodo Intermedio Temprano del valle de Acarí Preparación: L. M. Valdez 


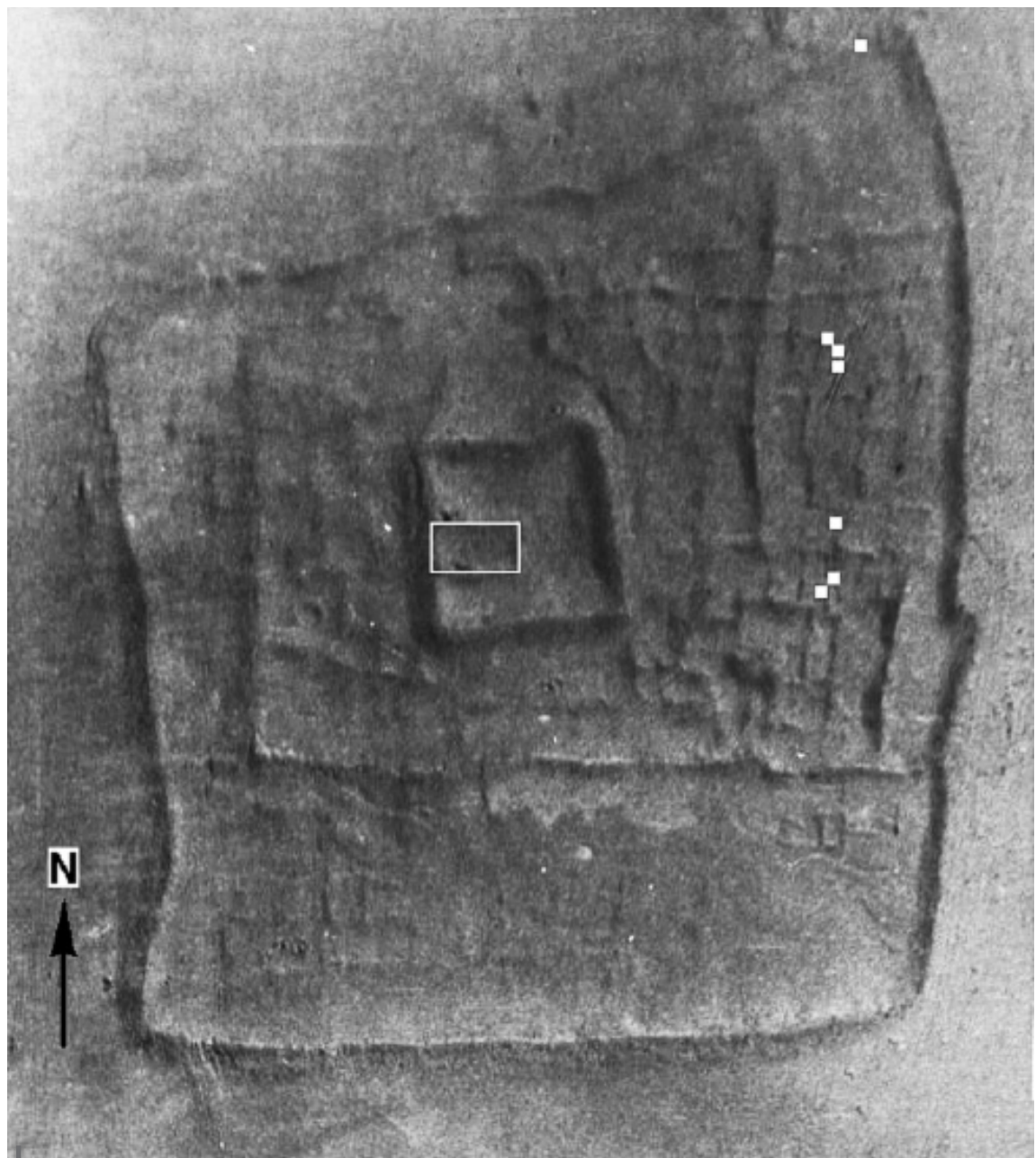

Figura 2 - Foto aérea del sitio arqueológico de Amato

Fuente: Servicio Aerofotográfico Nacional

Ningún trabajo anterior de excavación arqueológica se había efectuado en Amato. Por lo tanto, las primeras excavaciones realizadas durante las temporadas 2005 y 2006 tuvieron como objetivo fundamental verificar la ubicación temporal del sitio y la función de estructuras determinadas. Las excavaciones se concentraron al interior de la estructura rectangular; se establecieron 16 unidades de 4 × $4 \mathrm{~m}$. Tres unidades adicionales también fueron consignadas inmediatamente al lado este del recinto; dos fueron ubicadas al lado oeste; y otras fueron excavadas en la parte central este y en la esquina noreste del sitio arqueológico. Las excavaciones en la sección central este demostraron la ausencia de restos significativos; al parecer el sitio fue abandonado cuando esta sección aún estaba en proceso de construcción. Por otro lado, en la esquina noreste la excavación fue orientada a evaluar una sección del muro perimétrico. 


\section{LOS CUERPOS DECAPITADOS}

Trece deposiciones fueron halladas luego de los trabajos de excavación. La figura 3 ilustra su ubicación en relación al recinto rectangular, donde la letra $\mathrm{H}$ significa hallazgo y el número que la acompaña indica el orden del descubrimiento. Teniendo en cuenta el número de individuos presentes en cada una de las deposiciones y para los propósitos de esta discusión, los hallazgos son agrupados en tres categorías: la primera considera un cuerpo decapitado por cada deposición, son en total 5; la segunda trata acerca de deposiciones dobles y se han expuesto 2 ; finalmente, la tercera consigna las deposiciones de varios cuerpos, en total se han descubierto 6 .

\section{1. Hallazgos de la primera categoría}

Cada una de las 5 deposiciones de esta categoría contiene el cuerpo de un individuo que presenta distintas posiciones. Dos de ellos, uno excavado al noroeste de la unidad N15O27 (H11, fig. 4) y el otro al sureste de la unidad N16O28 (H3, fig. 5), se encontraron echados en posición ventral, con los brazos colocados a la altura de los hombros o cerca al pecho. Ambos cuerpos estaban a solo un metro de distancia entre sí y a su vez, a menos de un metro de una concentración mayor descubierta en la unidad N16O28 (H4). Por lo tanto, es posible que estos cuerpos formen parte de $\mathrm{H} 4$.

Otros dos cuerpos, uno excavado al noroeste de la unidad $\mathrm{N} 15 \mathrm{O} 26(\mathrm{H} 1$, fig. 3) y el otro en la intersección de las unidades N16O29 y N16O30 (H6, fig. 3) , fueron expuestos también estirados, pero en posición dorsal, con los brazos colocados cerca al pecho. En ambos casos se notó que las extremidades inferiores estaban ligeramente flexionadas. El hallazgo H6 (fig. 6) tenía los pies atados a la altura del tobillo. Finalmente, el quinto cuerpo de esta categoría fue excavado en la esquina noreste de la unidad $\mathrm{N} 15 \mathrm{O} 26(\mathrm{H} 2$, fig. 3) y fue encontrado recostado sobre su lado izquierdo, con las rodillas y los brazos flexionados hacia el pecho. A diferencia de los otros cuerpos, algunas partes del quinto hallazgo, especialmente las manos, estaban momificadas.

Cabe recalcar que, en contraste con los hallazgos discutidos por De Leonardis (2000) y Conlee (2007), el tratamiento que recibieron los cuerpos es diferente. Por ejemplo, solo en dos casos se pudo notar la presencia de tejidos, que nunca llegaron a cubrir los cuerpos en su totalidad. Del mismo modo, en ninguno de los casos había ofrenda alguna asociada a los cuerpos. Una excepción es el hallazgo de un instrumento cortante hecho en cuarzo que había sido envuelto en un retazo de tejido y abandonado cerca de H6. En general, los cuerpos de esta categoría parecen haber sido abandonados y enterrados en el mismo lugar donde fueron decapitados. En particular, la posición de los brazos de H3 (fig. 4) y H11 (fig. 5) sugiere que dichos cuerpos fueron abandonados en el mismo lugar donde se realizó la decapitación. 
Lidio Valdez

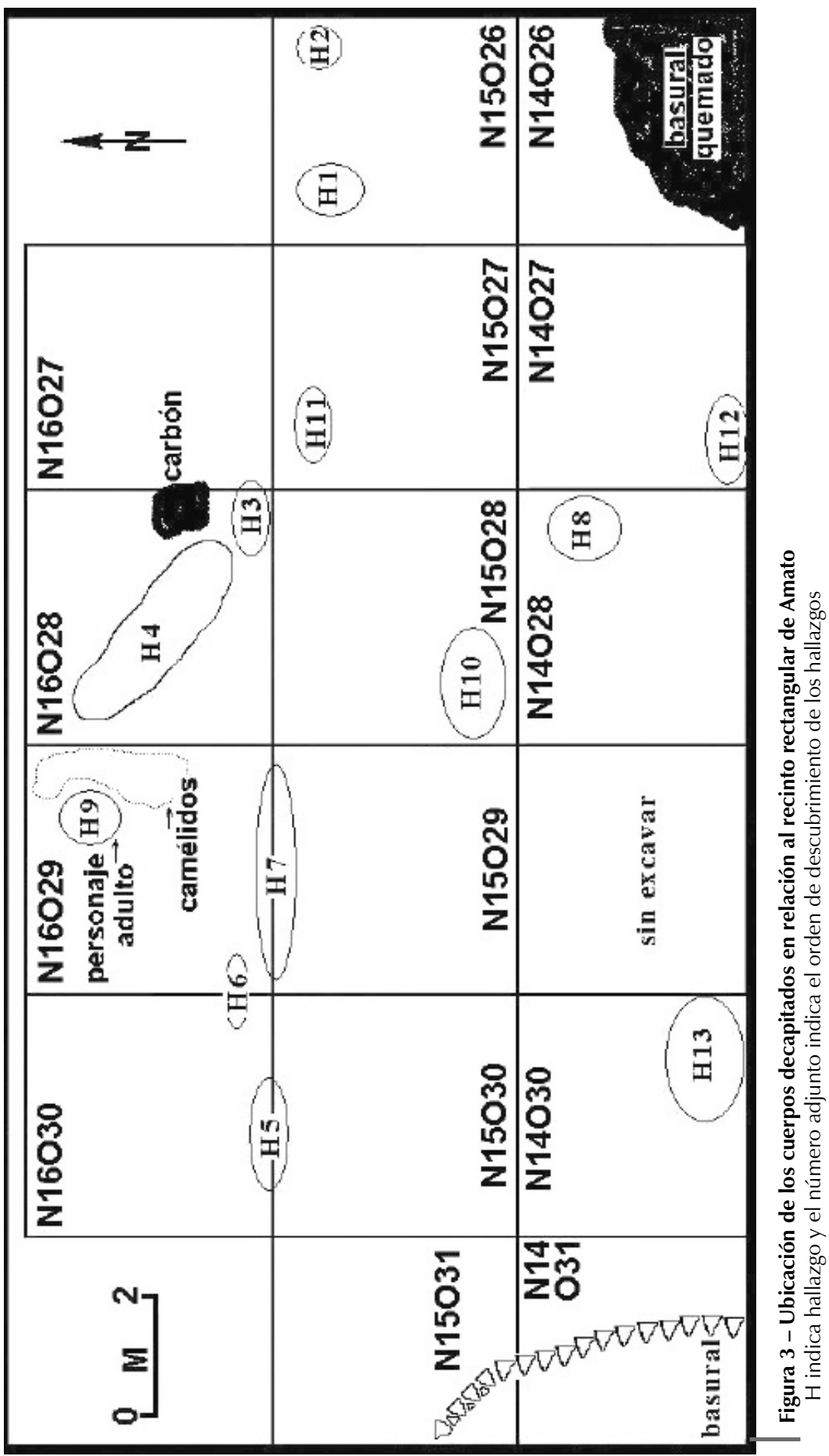




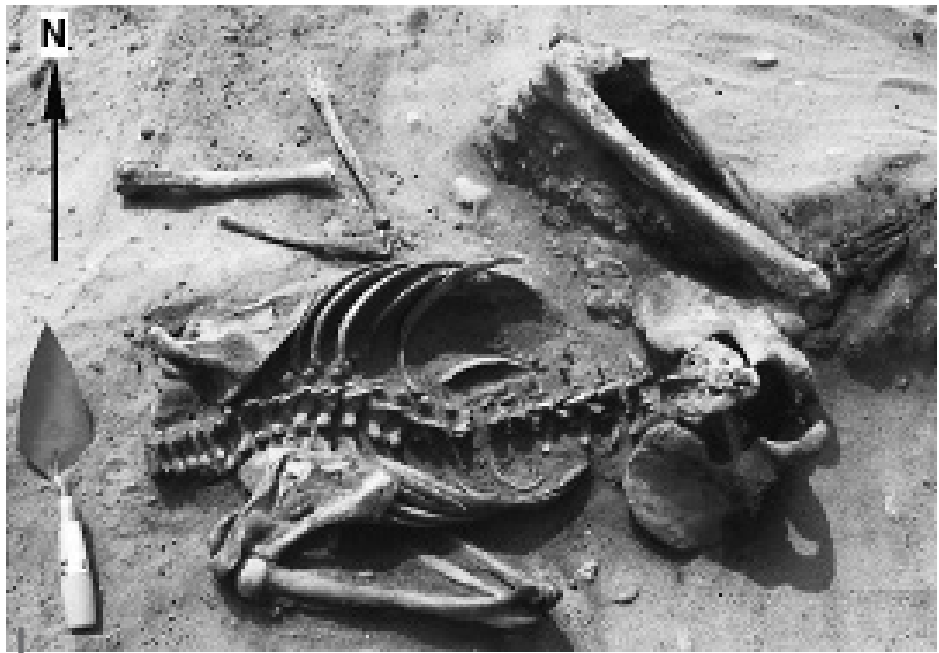

Figura 4 - Cuerpo decapitado expuesto al lado noroeste de la unidad N15027 (H11)

Foto por L. M. Valdez

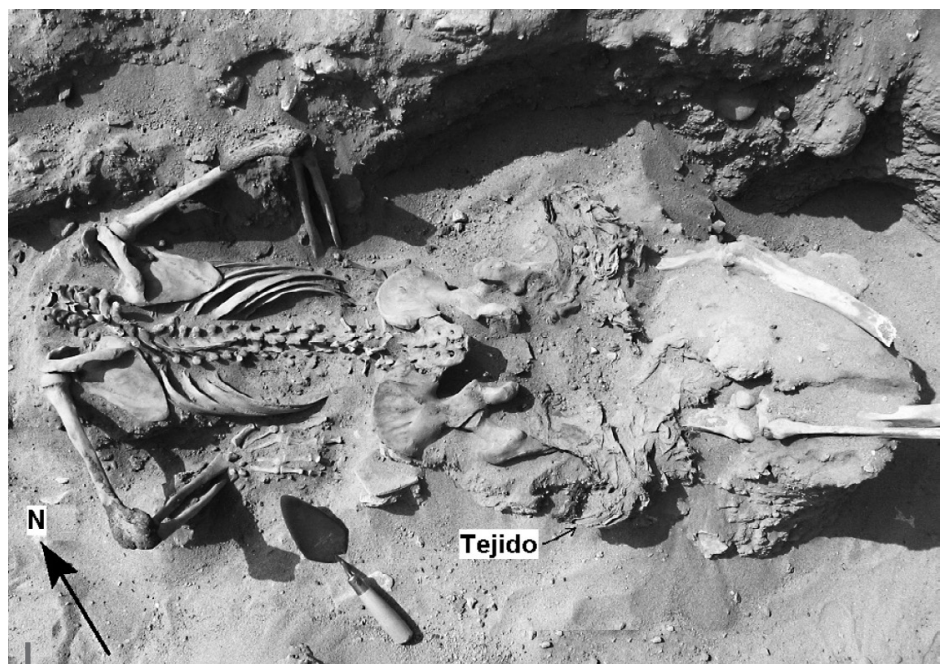

Figura 5 - Cuerpo decapitado expuesto al lado sureste de la unidad N16O28 (H3)

Foto por L. M. Valdez 

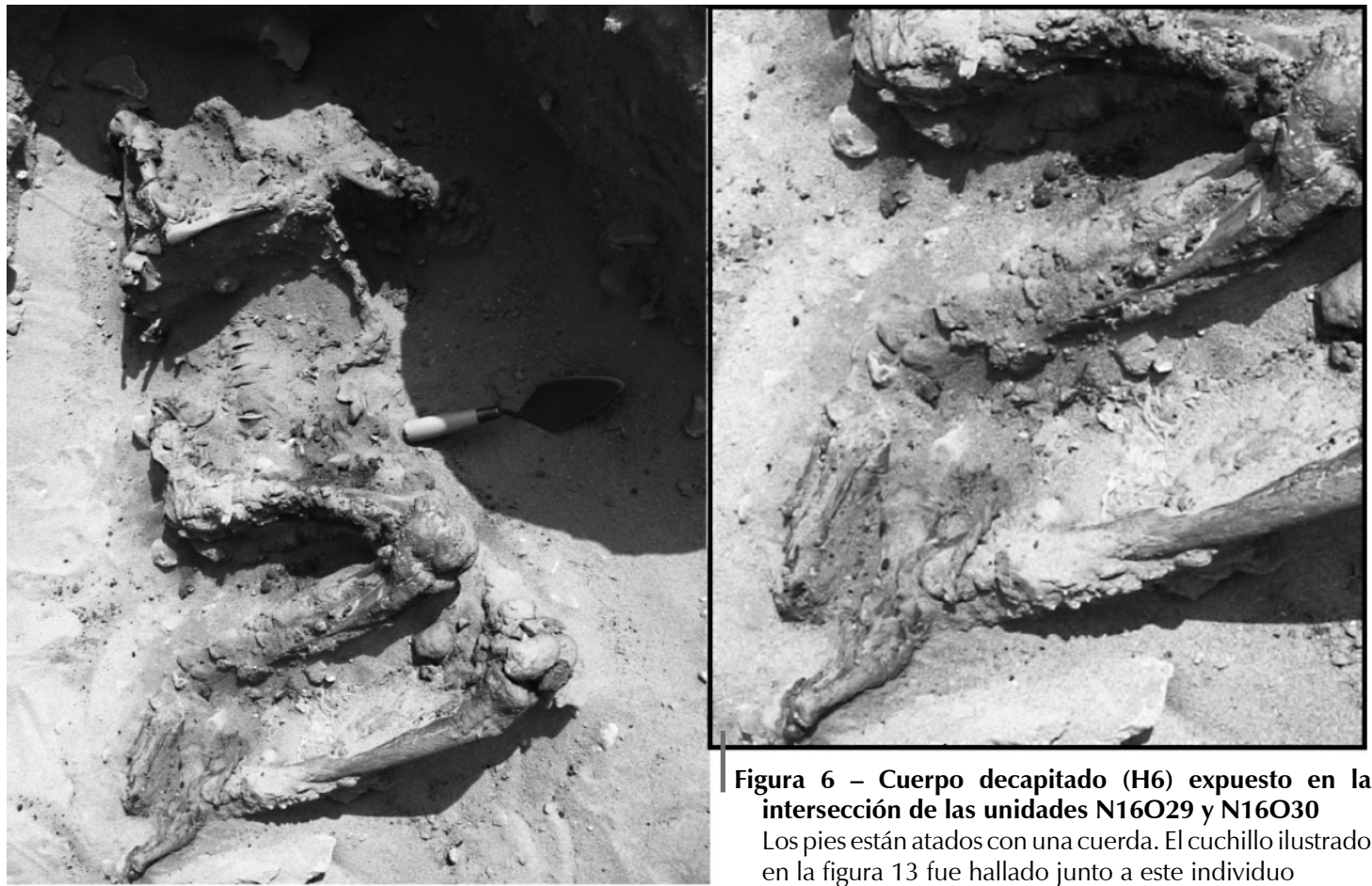

Figura 6 - Cuerpo decapitado (H6) expuesto en la intersección de las unidades N16O29 y N16O30 Los pies están atados con una cuerda. El cuchillo ilustrado en la figura 13 fue hallado junto a este individuo Fotos por L. M. Valdez

\section{2. Hallazgos de la segunda categoría}

Una de las deposiciones de esta categoría, excavada en la esquina suroeste de la unidad N14O27 ( 112 , fig. 3), cuenta con dos cuerpos parcialmente momificados después de la decapitación; fueron depositados sobre su lado derecho, con los brazos ligeramente estirados hacia el frente y las extremidades inferiores, un poco flexionadas (fig. 7). Uno de estos cuerpos pertenece a una mujer y presenta el estómago bastante pronunciado, lo que sugiere que: i) se encontraba en un estado de gestación bastante avanzado; ii) dio a luz no mucho antes de haber sido decapitada, o iii) sufrió un aborto como consecuencia de la decapitación. Este cuerpo también tenía los pies atados a la altura del tobillo. A diferencia de los anteriores, ambos casos fueron cubiertos con arena y esteras de fibra vegetal. No se hallaron tejidos ni ofrendas asociados.

El siguiente hallazgo (H9), cerca a la esquina noreste de la unidad N16O29, también contiene los cuerpos de dos individuos (H9, fig. 3). Este es un caso excepcional pues uno de los cuerpos no fue decapitado, pero sí estaba asociado al otro. El cuerpo que conserva su cabeza pertenece a un hombre adulto cuya edad promedio bordea los 60 años. A diferencia de los cuerpos decapitados, los restos del personaje adulto fueron depositados como si estuviera sentado, con las rodillas flexionadas hacia el pecho, los brazos colocados en los costados y las manos cruzadas a la altura del distal de la tibia y el peroné (Valdez, 2006: 7). 


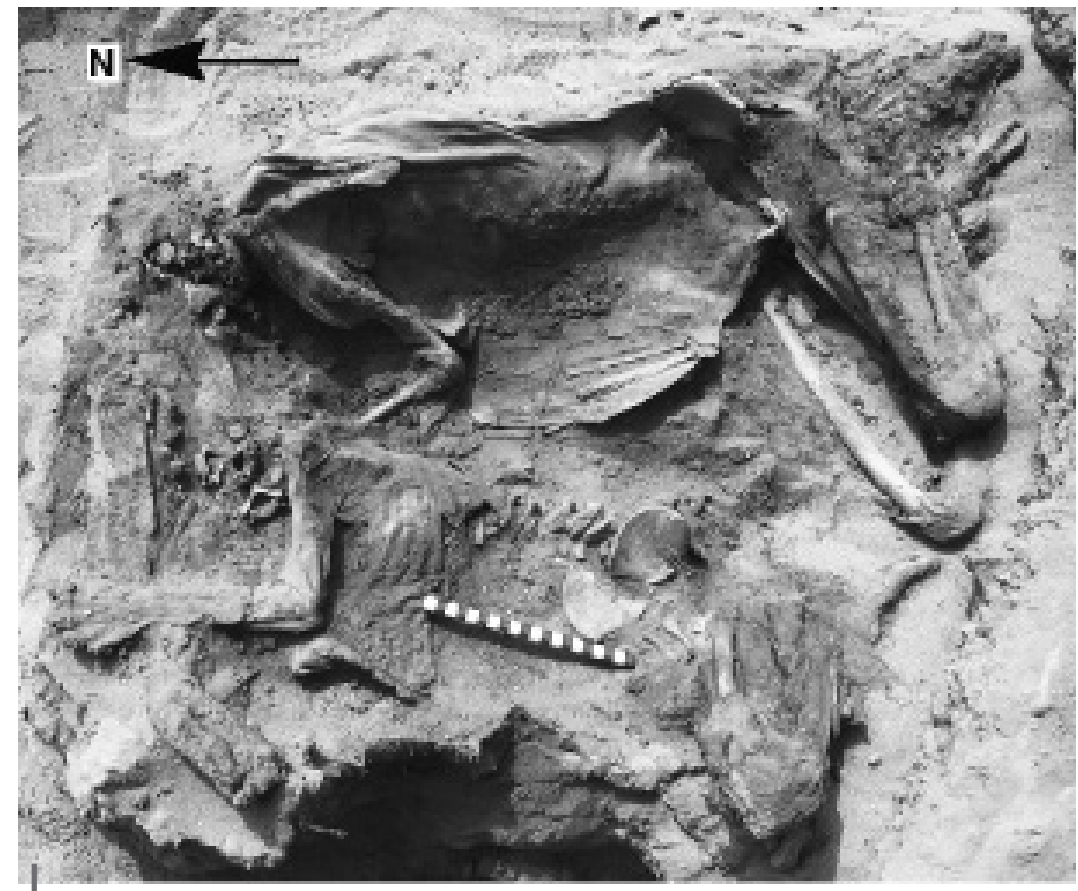

Figura 7 - Cuerpos parcialmente momificados al lado suroeste de la unidad N14O27 (H12)

Foto por L. M. Valdez

Además, el referido cuerpo había sido cubierto con un manto llano, sujeto con una soguilla de fibra vegetal a la altura del torso (fig. 8). Es importante resaltar que, de acuerdo a Isla \& Reindel (2006: 382), «nunca se ha documentado para un entierro del periodo Nasca un cuerpo amarrado con cuerdas...». Al igual que otros entierros del periodo Intermedio Temprano del valle de Acarí (Valdez, 2005b; 2005c; 2005d), el personaje adulto fue orientado hacia el norte. Estas características mortuorias indican que perteneció al valle de Acarí. Una muestra de carbón (madera) hallada junto a los pies del personaje adulto arrojó un fechado de 20 d.C. $( \pm 60)$.

Se hallaron varias ofrendas: un mate y vainas de maní (depositados cerca de los pies del individuo), cuatro camélidos colocados al lado derecho, y varias piezas de Spondylus, hallados en la parte posterior (Valdez, 2005a: 5). Además, el individuo poseía un collar fabricado con centenares de huesos radio-cúbito de alguna ave pequeña, adornado con varias decenas de cuentas hechas de la valva del Choromytilus chorus.

Al mismo tiempo, a la altura de la cabeza del personaje adulto se llegó a exponer el cuerpo estirado y en posición ventral de un individuo adulto cuya edad promedia los 40 años (fig. 8). Dicho individuo fue decapitado y colocado sobre una pequeña estera de fibra vegetal y cubierto parcialmente con otra estera similar (Valdez, 2006: 7). No se halló ninguna evidencia de tejido junto al decapitado, que 
parece haber estado desnudo. Este individuo recibió un tratamiento relativamente distinto al de los otros cuerpos decapitados referidos más adelante. Además, su proximidad al personaje sentado arroja la posibilidad que el individuo decapitado tal vez fue sacrificado en honor al personaje adulto y sus restos depositados cerca de él como una suerte de ofrenda. Dicha posibilidad sugiere, a su vez, que el individuo decapitado fue un antiguo líder de algún asentamiento vecino a Amato.

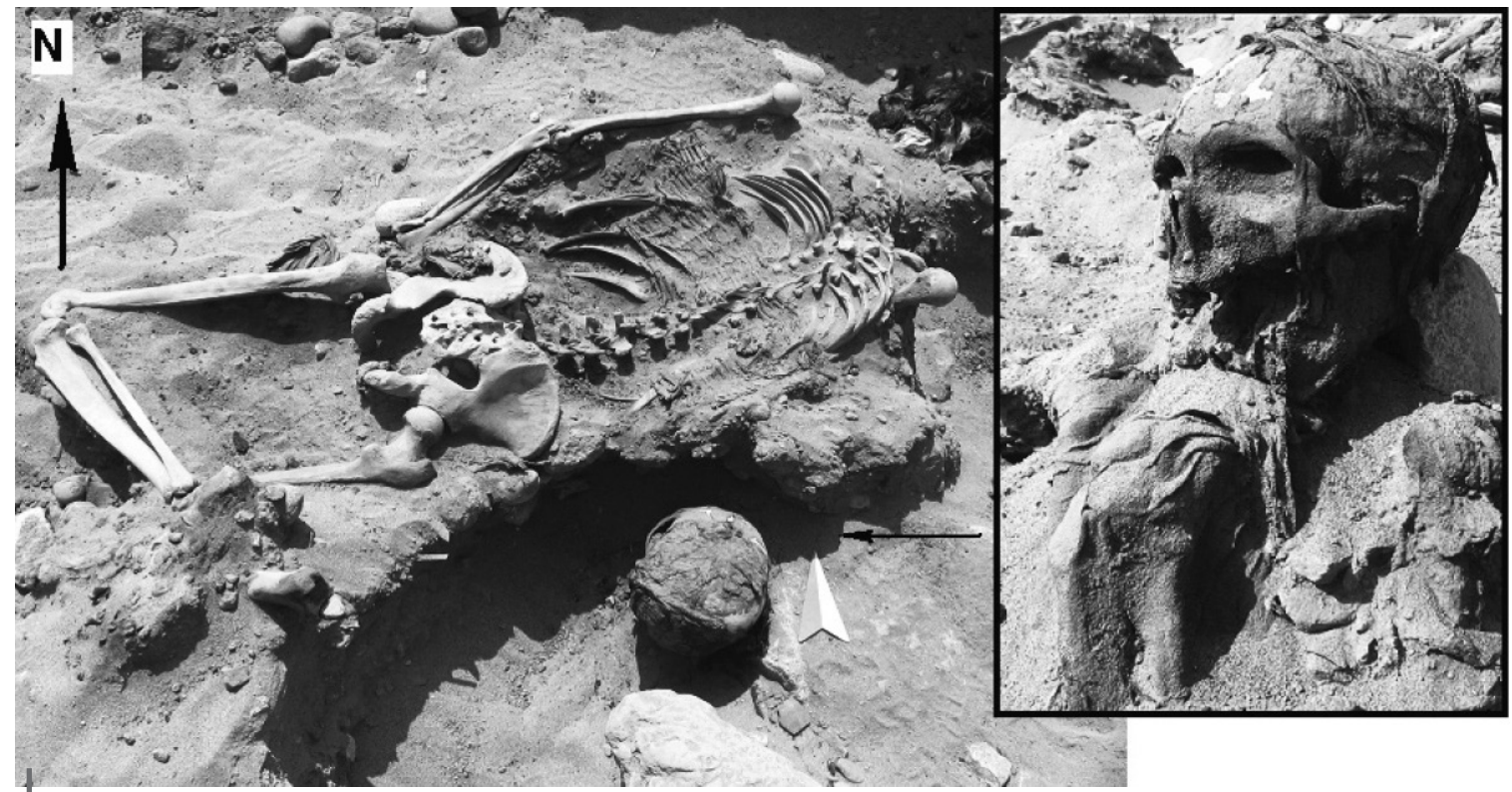

Figura 8 - Cuerpos expuestos al lado noreste de la unidad N16O29 (H9)

Al lado izquierdo, observe el cuerpo decapitado asociado a la cabeza del entierro (perteneciente a un personaje adulto, que se puede notar en el lado derecho). Fotos por L. M. Valdez

En cualquier escenario, se hace evidente que el entierro del personaje adulto (con cabeza) ocurrió primero. Luego, se procedió, quizás, con el asalto sorpresivo de asentamientos adyacentes para capturar las víctimas para el sacrificio. Una de tales víctimas habría sido el individuo decapitado al que nos referimos. Por lo tanto, la particularidad del personaje adulto, quien no solo recibió un tratamiento distinto, sino que también fue dotado de muchas ofrendas, incluyendo objetos exóticos, deja abierta la posibilidad que éste mantuvo en vida un status especial. En efecto, hasta hoy es el único caso en todo el valle de Acarí donde se observa un entierro dotado de muchas ofrendas, mientras que otros, pertenecientes al mismo periodo, rara vez poseen ofrendas (Valdez, 2005b; 2005c; 2005d; 2006). Por lo tanto, como se discute más adelante, existe la posibilidad que los cuerpos decapitados hallados al interior del recinto rectangular formen parte de los sacrificios humanos efectuados en honor al personaje adulto. 


\section{3. Hallazgos de la tercera categoría}

Cada una de las 6 deposiciones pertenecientes a la tercera categoría contiene los restos de varios cuerpos decapitados. La primera de ellas $(\mathrm{H} 4)$ fue expuesta en la unidad $\mathrm{N} 16 \mathrm{O} 28(\mathrm{H} 4$, fig. 3) y contiene varios individuos de ambos sexos y todas las edades decapitados y acumulados unos sobre otros, en algunos casos (fig. 9). Los cuerpos se encontraron estirados, manteniendo varias posiciones (dorsal, ventral y echados de costado) sin orden alguno. A pesar que los esqueletos mantienen un excelente estado de conservación, es notoria la ausencia de tejidos y a su vez, la presencia de muchas soguillas asociadas. En varias ocasiones se observó que las cuerdas aún estaban atadas al tobillo, lo que sugiere que los individuos decapitados tenían los pies atados. Al sureste de la unidad donde se encontraron los restos decapitados de $\mathrm{H} 4$, también se expuso una concentración de carbón (fig. 3) que indica que el fuego fue parte de los rituales de decapitación. Una muestra de carbón recuperada de este contexto arrojó un fechado de 15 d.C. $( \pm 60)$. Es importante recordar que dos de los esqueletos decapitados, hallados ligeramente aislados, estaban cerca de toda esta conglomeración de cuerpos.

Una segunda deposición, excavada en el lado noreste de la unidad N14O28 (H8, fig. 3), incluye los cuerpos de varios individuos (fig. 10). A diferencia de la anterior, los cuerpos fueron depositados en una fosa excavada sobre la formación de arena compacta y donde los cuerpos fueron acumulados unos encima de otros. Algunos cuerpos de la parte superior estaban casi desarticulados y los huesos más pequeños, como las falanges, están ausentes. Ello sugiere que estos cuerpos permanecieron expuestos por más tiempo y recién fueron enterrados cuando ya estaban en un estado de descomposición relativamente avanzado. Evidencias de tejidos u ofrendas tampoco fueron halladas, excepto la presencia de algunos adobes que habían sido depositados sobre los cuerpos.

Una tercera deposición que también contenía los restos de varios individuos fue expuesta en la parte suroeste de la unidad N15O28 (H10, fig. 3). Los cuerpos decapitados fueron depositados en un pequeño hoyo excavado sobre la formación de arena compacta. También mantenían distintas posiciones y algunos eran colocados encima de otros. Lo notable de este hallazgo es que los cuerpos fueron depositados directamente sobre el fuego, algunas llegaron incluso a quemarse.

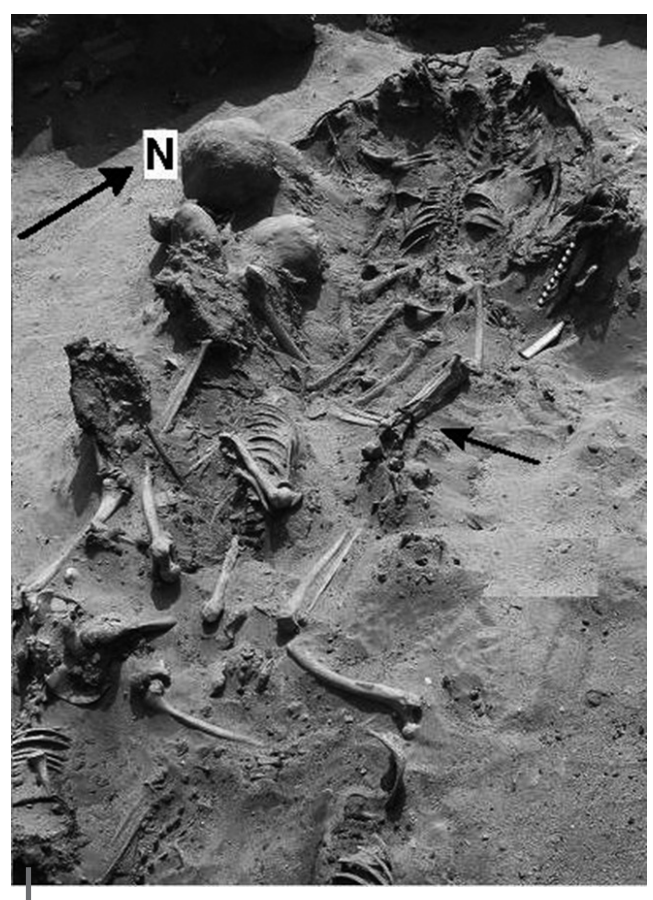

Figura 9 - Cuerpos decapitados expuestos en la Unidad N16O28 (H4)

12 cuerpos fueron recuperados en este contexto Foto por L. M. Valdez 


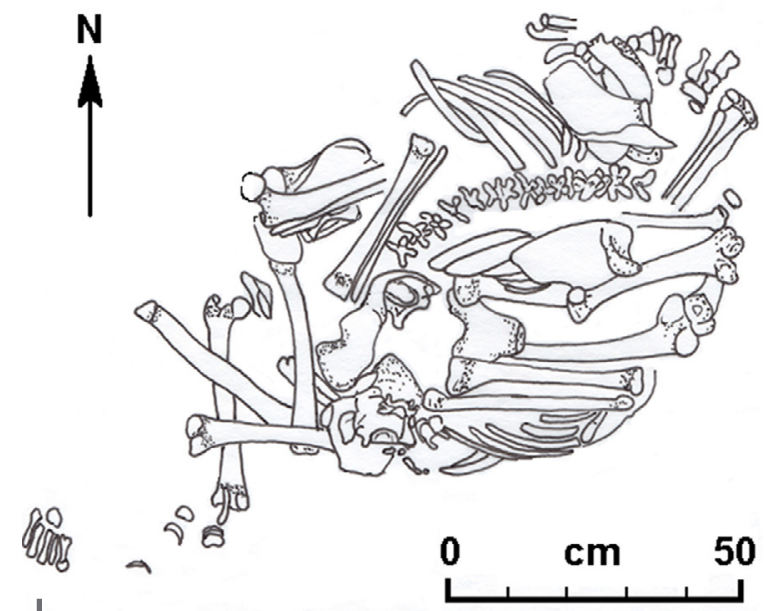

Figura 10 - Cuerpos decapitados hallados al lado noreste de la unidad N14028 (H8)

Preparación: L. M. Valdez
Una acumulación de plantas denominadas «Cola de caballo» (Equisetum) habría sido depositada para crear el fuego. Excepto uno, los cuerpos de esta deposición pertenecen a individuos jóvenes, incluyendo infantes. Una cuarta deposición (H7) fue expuesta en la intersección de las unidades N15O29 y N16O29 (H7, fig. 3). En este caso se observó que los cuerpos fueron depositados extendidos y manteniendo distintas posiciones (dorsal, ventral y de costado) y en algunos casos, unos encima de otros. Como en los casos anteriores, resalta la ausencia de evidencias de tejido; mientras que, en un caso, se notó la presencia de una cuerda atada al tobillo. Existen partes momificadas de los cuerpos, especialmente de las manos y los pies. No se hallaron artefactos identificables como ofrendas. Por su proximidad, el individuo de $\mathrm{H} 6$ probablemente forma parte de este contexto.

La quinta deposición (H5), expuesta en la intersección de las unidades N15O30 y N16O30 (H5, fig. 3), mantiene las mismas características que las anteriores en lo referido a los cuerpos y su ubicación y posición (fig. 11); aunque se observaron algunas muestras de tejidos, concentrados a la altura de la pelvis, que sugieren que las víctimas estaban parcialmente cubiertas. También se encontraron soguillas de fibra vegetal atadas al tobillo, lo que indicaría que estos individuos recibieron el mismo trato que el resto de los decapitados.

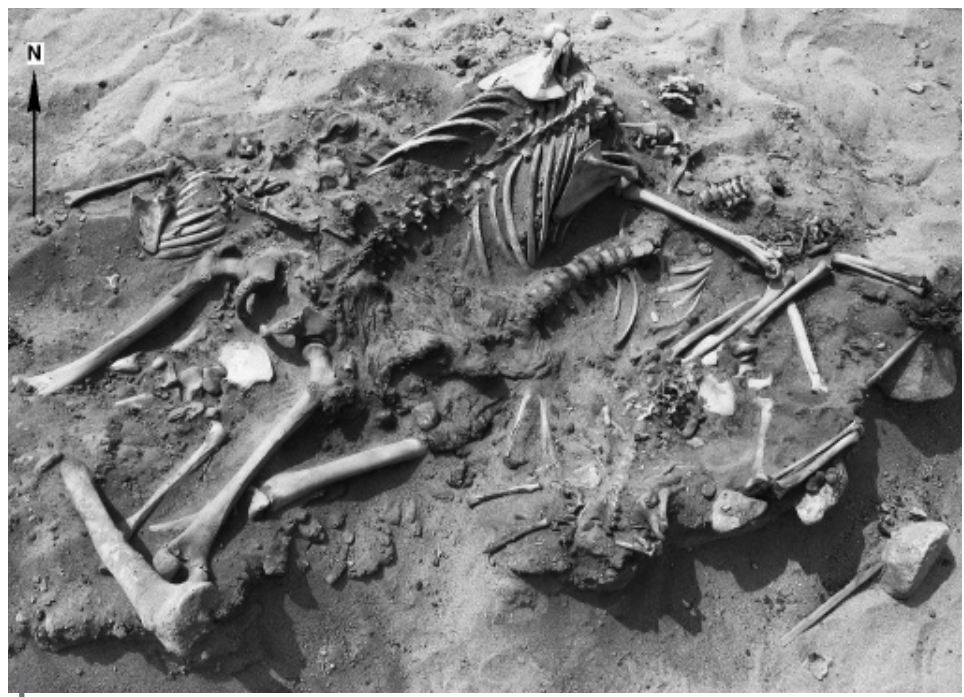

Figura 11 - Cuerpos decapitados en la intersección de las unidades N15O30 y N16O30 (H5)

Fotos por L. M. Valdez 
La última deposición fue expuesta en el lado sureste de la unidad N14O30 (H13, fig. 3). Este hallazgo fue removido por los huaqueros, lo que alteró la disposición original de los cuerpos. A pesar que los cuerpos estaban en parte desarticulados — probablemente como resultado de la intervención de los huaqueros—, algunos esqueletos aún mantenían una perfecta articulación anatómica. No se encontraron evidencias de tejido u otros artefactos.

En general, los cuerpos decapitados habrían sido depositados en varios lugares al interior del recinto rectangular. Esta distribución sugiere que cada una de estas deposiciones representa, al parecer, eventos separados pero efectuados dentro de un periodo relativamente corto. En efecto, antes de las decapitaciones, todo el recinto había sido barrido y los desechos fueron depositados en las esquinas sureste y suroeste. La primera deposición habría sido totalmente quemada, mientras que la segunda fue cubierta con ramas de plantas silvestres y arena. Para el caso de la segunda acumulación de desechos, se habían alineado adobes cónicos para separar y aislar el basural del resto del recinto. Entre los desechos allí depositados destacan los restos orgánicos de plantas y animales, además de tejidos, soguillas y fragmentos de cerámica — muchos de ellos poseían una decoración de estilo local, perteneciente a la tradición Huarato (Valdez, 1998; 2000). Dicho estilo comparte algunos rasgos en cuanto a forma con el estilo Nasca Temprano, pero su manufactura, acabado y decoración varían significativamente y tiende a ser menos sofisticado-.

Un segundo aspecto que apoya nuestra hipótesis de los cuerpos decapitados como parte de eventos separados, es el hecho que, durante todo ese tiempo, el recinto central permaneció limpio. Del mismo modo, es interesante notar que en ningún caso las deposiciones llegaron a interrumpir otras; quizás las personas encargadas del entierro conocían la ubicación exacta. Esta inferencia también indica que los actos de decapitación tal vez se efectuaron dentro de un periodo que apenas duró semanas o algunos meses. Además, recibieron tratamientos relativamente distintos: por ejemplo, los cuerpos de $\mathrm{H} 10$ fueron depositados directamente sobre el fuego, mientras que los de $\mathrm{H} 12$ fueron parcialmente cubiertos con esteras de fibra vegetal. Estas diferencias, aunque sean mínimas, sugieren eventos separados. Es posible que dichos actos se realizaran siguiendo la muerte del personaje adulto — esta postura será retomada en el acápite final—.

\section{LAS EVIDENCIAS DE DECAPITACIÓN}

Salvo la deposición H13 —intervenida por los huaqueros-y la H8 — con algunos esqueletos parcialmente desarticulados-, la mayoría de los restos de los humanos decapitados de Amato se encontraron en un excelente estado de conservación. En varias ocasiones el tejido blando del cuerpo (momificado) aún está presente. Además de las pocas excepciones, varios esqueletos aún mantienen su posición anatómica (articulados). Los huesos tampoco muestran evidencias de prolongadas exposiciones al sol: la mayoría de los cuerpos fueron enterrados o cubiertos con arena, poco tiempo después de la decapitación. El caso de H8 es particular pues 
la mayoría de los esqueletos estaban parcialmente desarticulados. Al parecer, los cuerpos de $\mathrm{H} 8$ fueron enterrados en pleno proceso de descomposición avanzada, pues los esqueletos estaban desarticulados y las falanges, ausentes. Sin embargo, incluso los restos de $\mathrm{H} 8$ no parecen haber estado expuestos por mucho tiempo, pues los huesos no aparecen «blanqueados» por el sol. Todos estos datos juntos permiten sostener que los cuerpos de $\mathrm{H} 8$ representan el último sacrificio -asumiendo que se realizaron varios sacrificios y que previamente los cuerpos fueron enterrados antes del siguiente proceso de decapitación-.

Del análisis osteológico de los cuerpos decapitados de Amato (Valdez et al., 2006) se desprende que representan a una población que incluye individuos de todas las edades (infantes y recién nacidos también) y de ambos sexos. El anterior estudio de las cabezas trofeo, provenientes de contextos pertenecientes al Nasca Temprano, ya había arrojado resultados similares (Coehlo, 1972; Baraybar, 1987; Drusini \& Baraybar, 1991; Williams et al., 2001) y el análisis reciente confirma dichos resultados —debemos recordar que los hallazgos de Amato son contemporáneos con el periodo Nasca Temprano-.

La ausencia de cráneos vuelve únicos los hallazgos de Amato. Con excepción del individuo adulto (H9) que no fue decapitado, todos los cuerpos hallados al interior de la estructura rectangular no tenían sus respectivas cabezas; además carecían de huesos atlas, axis y otros cervicales inmediatos —acaso tales huesos fueron removidos junto con las cabezas - El primer cervical presente con el resto del cuerpo, por lo general, presenta claros cortes (fig. 12). La víctima más joven que presenta cortes en la vértebra pertenece a la categoría de feto/recién nacido ( \pm 3 meses de vida).

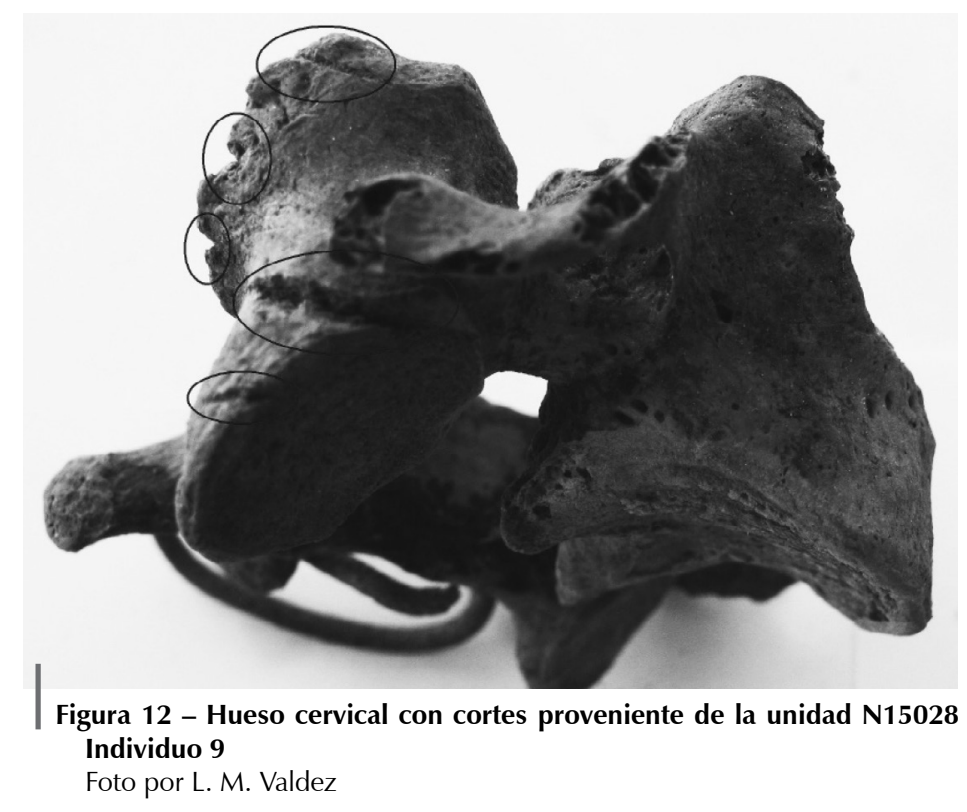


Dichos cortes son indicadores concretos de que las cabezas fueron separadas del resto del cuerpo mientras la parte blanda aún estaba presente. De lo contrario, sin el tejido blando, no hubiera sido necesario el uso de instrumento alguno para separar la cabeza del resto del cuerpo. Esto implica, por lo tanto, que las víctimas probablemente perdieron la vida como consecuencia de la decapitación. Un escenario alterno sería la separación de las cabezas de individuos recientemente muertos, como resultado del abuso físico al que fueron sometidos. En ambos casos, los cortes atestiguan el uso de instrumentos cortantes durante la decapitación, lo que sugiere que los cuerpos estaban perfectamente articulados. Estos son algunos de los indicadores que otros especialistas también consideran como evidencia de la decapitación (Milner, 1995: 230; Verano, 2001: 168; Conlee, 2007: 441). En contraste, la separación de las cabezas de individuos muertos no coincide con los cortes referidos en esta sección, aunque tendría como resultado la desarticulación de los esqueletos.

Tal como se recalcó en la sección anterior, junto al cuerpo decapitado ubicado entre las unidades N16O29 y N16O30 (H6) se halló un instrumento cortante envuelto en un retazo de tejido. Un extremo del instrumento es bastante filudo (fig. 13) y deja abierta la posibilidad que éste, u otro instrumento similar, haya sido utilizado en la decapitación. Por lo tanto, existe

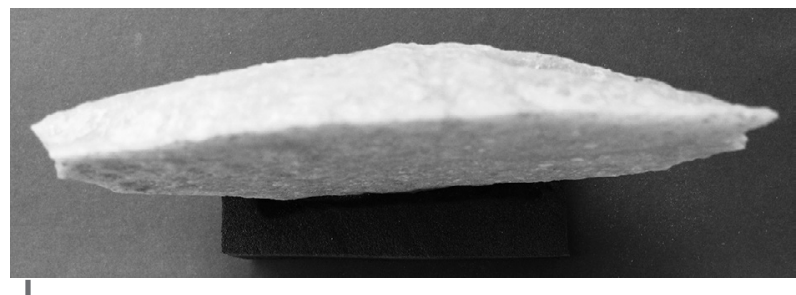

Figura 13 - Instrumento cortante asociado al individuo expuesto entre las unidades N16029 y N15030 Foto por L. M. Valdez la posibilidad que los cortes observados en los huesos cervicales tal vez fueron producidos por este instrumento. Antes, una cerámica Nasca, actualmente depositada en el Museo Amano de Lima, fue la única muestra que, de alguna manera, arrojó indicios sobre la forma en que las cabezas fueron físicamente separadas de los cuerpos (Proulx, 2001: 127-129; Silverman \& Proulx, 2002: 232).

\section{TRATAMIENTO DE LOS CUERPOS}

Hasta hace poco, las únicas evidencias de cuerpos sin cabezas fueron descubiertas por De Leonardis (2000) y Conlee (2007), pertenecientes a las fases Nasca 3 y Nasca 5 , respectivamente. Ambos cuerpos presentaban posiciones distintas y recibieron tratamientos diferentes. El primero fue envuelto con un manto y depositado en posición dorsal y extendida, mientras que el segundo estaba sentado. A pesar de dichas diferencias, ambos cuerpos recibieron ofrendas al igual que otros entierros Nasca. A diferencia de estos dos ejemplos, los cuerpos decapitados de Amato muestran un tratamiento completamente distinto. A excepción de la presencia de algunas esteras de fibra vegetal asociadas a algunos cuerpos, la mayoría de los cuerpos de Amato no fue envuelta en tejidos y tampoco recibieron ofrendas. 
En un escenario distinto a los dos ejemplos citados, los cuerpos provenientes de Amato presentan evidencias de haber sido tratados como cautivos. En primer lugar, las muestras de tejidos (vestimenta) aparecen ocasionalmente, lo que indicaría que las víctimas estuvieron desnudas, o semidesnudas, momentos previos y durante la decapitación. En segundo lugar, en varias ocasiones los pies y las manos de los decapitados estaban atados (Valdez et al., 2006), sugiriendo que las víctimas no estaban en condiciones de defenderse y menos de escapar. Por lo expuesto, la decapitación parece haber sido forzosa.

Del mismo modo, el estudio inicial de los cuerpos decapitados de Amato revela la presencia de muchas lesiones y fracturas de los huesos del brazo, especialmente de la radio y el cúbito (fig. 14), así como también del omoplato, las costillas y en algunos casos, las extremidades inferiores (Valdez et al., 2006). Las fracturas observadas en los brazos, por lo general, aparecen en los huesos del lado izquierdo, indicando que fueron producidas por golpes laterales de un probable garrote, o algo similar, que impactaron directamente sobre el cuerpo, cuando las víctimas trataban de protegerse con sus brazos en pleno enfrentamiento. Los huesos fracturados, a excepción de uno, no llegaron a soldarse pues fueron quebrados poco tiempo antes de la muerte. La ocurrencia de las lesiones es una evidencia conclusiva de la violenta captura y la posterior decapitación. Solo después de un arduo y sangriento enfrentamiento, las víctimas (hombres, mujeres y niños) fueron finalmente capturadas. Por su parte, la extraña presencia de fracturas soldadas sugiere que la población decapitada no participó con anterioridad en enfrentamientos similares —veáse Milner (1999: 115) para una discusión similar-. En general, estas son evidencias novedosas pues no se había registrado algo similar.

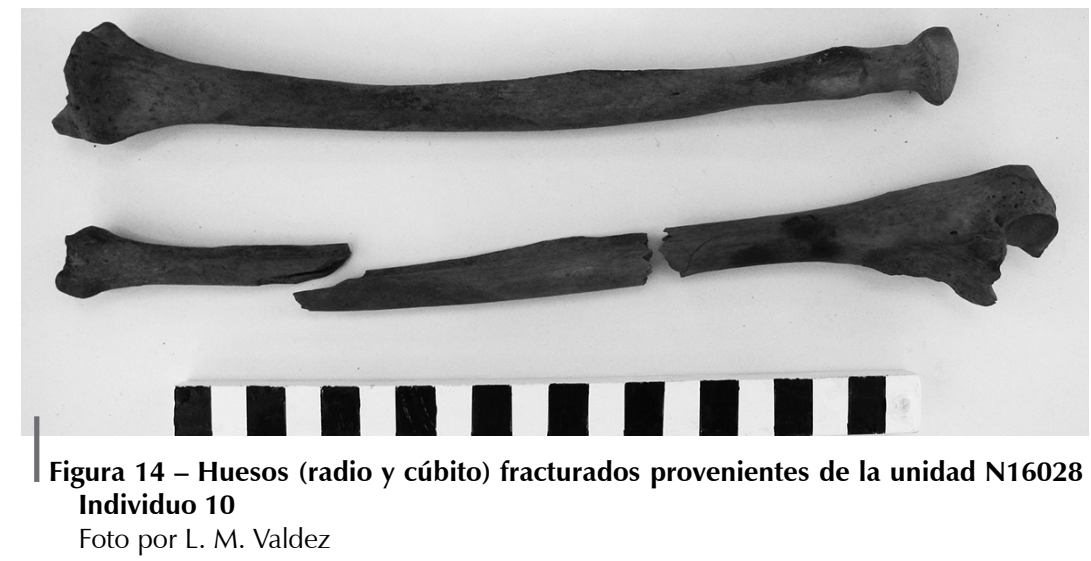

Un aspecto difícil de determinar es si las víctimas fueron residentes de Amato, capturados y decapitados en su propio asentamiento, o de alguna población vecina, quienes luego de haber sido capturados fueron trasladados hasta Amato para la decapitación. Futuros estudios ayudarán a esclarecer esta incógnita, aunque por ahora, el escenario más probable es el de un personaje adulto, residente de 
Amato, y los asaltos sorpresivos en determinados asentamientos vecinos después de su muerte, para capturar víctimas. De ser válida esta sugerencia, la decapitación humana y la obtención de las cabezas trofeo tendrían relación con la muerte de personajes de prestigio.

En cualquier escenario, los cuerpos decapitados de Amato son producto de una acción violenta: una población definitivamente herida (con huesos fracturados), indefensa (con manos y pies atados) y finalmente forzada a la decapitación (Valdez, 2007). Para poner en perspectiva las evidencias provenientes de Amato, en la siguiente sección se hace referencia a los asentamientos que se establecieron en el valle al mismo tiempo que el sitio de Amato. Dicha consideración refuerza la idea que las condiciones sociales en Acarí durante las fases iniciales del periodo Intermedio Temprano fueron violentas.

\section{ASENTAMIENTOS DEFENSIVOS DE ACARI}

Durante las fases iniciales del periodo Intermedio Temprano, Amato y otros ocho asentamientos se establecieron en la parte baja del valle de Acarí (Valdez, 1998; 2000; 2006). Así como Rowe (1963) resaltó, en un principio, la presencia de grandes muros perimétricos como un rasgo sobresaliente de todos estos asentamientos, en los sitios más conservados, como Amato, los muros encierran por completo los sitios arqueológicos (Valdez, 2006: 4). Con el objetivo de evaluar dichas construcciones, recientemente se han excavado secciones de los referidos muros en los sitios de Huarato y Amato. Previamente se realizó la limpieza de una sección de los muros perimétricos de Tambo Viejo y Monte Grande Alto. Todos estos trabajos permitieron determinar que los muros perimétricos — no obstante las diferencias de un sitio a otro- fueron construidos con adobes de diversas formas y piedras traídas desde las inmediaciones del cauce del río. Todas estas actividades habrían requerido un despliegue enorme de esfuerzo y energía humana, lo que sugiere que tales sistemas defensivos eran indispensables, debido a las tensas y violentas condiciones sociales que existieron en el valle. Además, junto a los referidos muros, en la parte externa se observan grandes zanjas producidas al extraer la tierra para elaborar los adobes. Keeley et al. (2007: 58) sostienen que las zanjas asociadas a los muros perimétricos también cumplen funciones defensivas.

La presencia de dichos sistemas defensivos en cada uno de los sitios de Acarí y sobre todo la energía invertida en su establecimiento - a la luz de las evidencias de decapitación proveniente de Amato- sugieren que, durante las fases iniciales del periodo Intermedio Temprano, las relaciones entre los asentamientos fueron tensas y la seguridad y defensa se volvieron prioritarias (Valdez, 2007). Por ello, los sistemas defensivos se orientaron a salvaguardar la seguridad de los residentes. Varios especialistas consideran que estructuras como muros y fortificaciones denotan defensa y son indicadores de conflicto (LeBlanc, 1999: 56; Milner, 1999: 111; Flannery \& Marcus, 2003; Elliot, 2005: 299; Arkush \& Stanish, 2005: 15; Keeley et al., 2007: 57; Parkinson \& Duffy, 2007: 118; Allen \& Arkush, 2006: 7). 
Además de los muros perimétricos, existen espacios «vacantes» entre un sitio y otro, establecidos, al parecer, como sistemas de defensa adicionales. Una excepción fue la de Boca del Río y Chaviña, sitios establecidos cerca de la desembocadura del río Acarí pero controlando los lados opuestos. Debido a dicha proximidad, Boca del Río parece haber sido abandonado y su población, tal vez, fue absorbida por Chaviña. Entre Amato y Coquimbo se intentó establecer un nuevo asentamiento (Molino), cuya construcción no fue concluida porque Coquimbo estaba a corta distancia. Los asentamientos más próximos, a menudo, se establecieron en la margen opuesta del río y sugieren que esta distribución fue, en gran parte, influenciada por el conflicto que existió en el valle. Según Arkush \& Stanish (2005), los espacios «vacantes» son otro indicador de la existencia de alguna forma de conflicto. Al culminar las fases tardías del periodo Intermedio Temprano, muchos de estos espacios fueron ocupados y los nuevos asentamientos no fueron fortificados.

Finalmente, los asentamientos no solo estaban separados por espacios vacíos, sino que, en lo posible, fueron establecidos para controlar las bandas opuestas al río. Así sucedió entre Huarato y Amato, Amato y Coquimbo, Tambo Viejo y Elsar, y Monte Grande Alto y Chaviña. Las únicas excepciones son los casos de Coquimbo y Tambo Viejo y Elsar y Monte Grande Alto. Esta distribución espacial de los asentamientos parece reflejar las tensas relaciones que predominaron en este valle durante las fases iniciales del periodo Intermedio Temprano. El grado de dichos conflictos solo se puede percibir en las evidencias de decapitación, provenientes de Amato, y en el esfuerzo desplegado al construir los muros perimétricos. Por lo tanto, no cabe duda que los pobladores de los asentamientos del valle de Acarí establecieron diversos sistemas defensivos como respuesta directa a la situación que existió en el valle. Allen \& Arkush (2006: 6) comentan que esas relaciones se reflejan en los patrones de asentamiento.

Mientras los sitios del valle de Acarí, pertenecientes a las fases tempranas del Intermedio Temprano, son conglomerados y están dotados de sistemas defensivos en forma de muros perimétricos y zonas vacantes, no existe un solo asentamiento Nasca Temprano con tales características (Browne et al., 1993: 290; Silverman, 2002: 147; Conlee \& Schreiber, 2006: 97). La diferencia entre Acarí y Nasca permite plantear que, a lo largo de la costa sur, se dieron diferentes escenarios sociales, algunos más violentos que otros. De acuerdo a las evidencias discutidas, podemos deducir que la situación del valle de Acarí fue bastante más conflictiva que los valles del norte. Dentro de estos contextos se realizaron las prácticas de la decapitación, no necesariamente como una respuesta a causas comunes. Contrario al caso de Acarí, el conflicto parece no haber sido la fuente de las cabezas trofeo del Nasca temprano (Browne et al., 1993: 290).

Dentro de la disciplina antropológica en general, existe un consenso en advertir que la presencia de asentamientos dotados de sistemas defensivos y ubicados en lugares de aparente posición estratégica, refleja las condiciones sociales del tiempo en que fueron ocupados (Allen \& Arkush, 2006: 6; Parkinson \& Duffy, 2007: 118). Es decir, si las condiciones sociales son violentas y la necesidad de seguridad prima, los asentamientos estarán ubicados en lugares estratégicos además de estar equipados con sistemas defensivos, como los muros perimétricos 
(Flannery \& Marcus, 2003). Siguiendo esta premisa — sumada a la presencia de las zonas «vacantes» y de los cuerpos decapitados de Amato-, el diseño y la ubicación de los asentamientos establecidos en el valle de Acarí durante las fases tempranas del periodo Intermedio Temprano posiblemente sugieren que fueron ocupados en tiempos de conflicto.

¿Cuáles fueron las razones que crearon el conflicto en Acarí? ¿A qué obedece la presencia de asentamientos fortificados en Acarí, mientras en sitios similares como Nasca, no existen? Es preciso enfatizar que, como parte del desierto que se extiende a lo largo de la costa peruana, la costa sur en general es árida y los suelos cultivables son limitados (Carmichael, 1998: 216; De Leonardis, 2000: 364; Conlee \& Schreiber, 2006: 96-97; Silverman, 1996: 99; Vaughn, 2005: 116). Dicha limitación, sin embargo, es más acentuada en el valle de Acarí —en comparación con Nasca, por ejemplo- debido a que el río Acarí, que irriga el valle, recorre gran parte de su tramo entre las estribaciones de las montañas - en particular, las montañas se encuentran solo a corta distancia del mar- y no forma suelos agrícolas amplios como en los otros valles ubicados más al norte. Solo en los últimos 35 kilómetros de su recorrido, el río se abre hacia un área amplia y plana (el desierto); sin embargo, hace un corte profundo en el desierto. En el terreno donde se ubican estos sitios solo encontramos pequeñas parcelas de terrenos útiles para fines agrícolas (una buena extensión de las mismas están sujetas a inundaciones anuales). Fuera del curso del río solo hay cerros secos, el desierto y el mar (fig. 15).

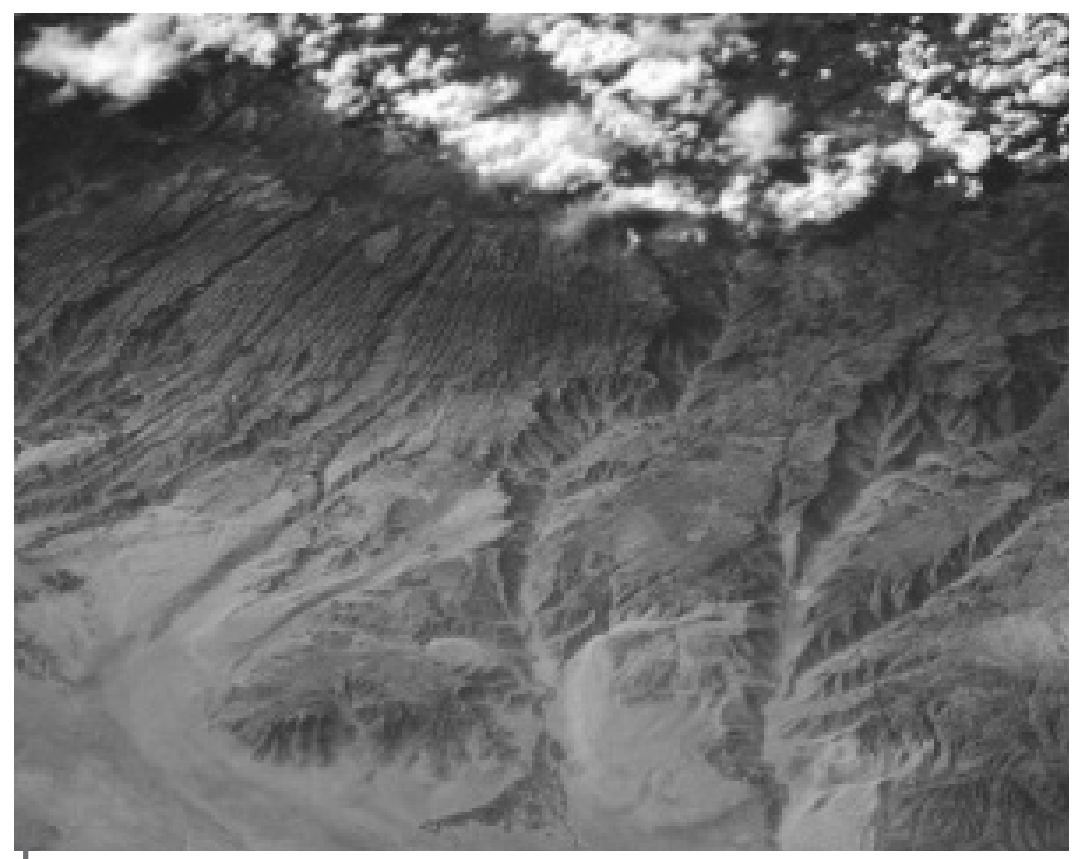

Figura 15 - Mapa satelital del valle de Acarí mostrando la estrecha formación del valle Publicado previa autorizacion de la NASA 
Los recientes estudios arqueológicos en Acarí vienen demostrando que la subsistencia de los asentamientos establecidos durante las fases tempranas del periodo Intermedio Temprano, incluido Amato, estaba basada en los productos agrícolas (Valdez, 2007). Dicha particularidad, en un valle con limitados suelos cultivables, sugiere la posibilidad de que el conflicto, manifestado en sitios fortificados y cuerpos decapitados, se originó por la escasez de recursos agrícolas. Previamente, Proulx (2001: 128) ya había sostenido que la decapitación humana era el resultado de los conflictos que se originaron por los limitados recursos agrícolas. En efecto, en un valle circunscrito como Acarí es posible que toda intención de acceder a los recursos limitados de asentamientos vecinos, llevara consigo el potencial de generar conflicto (Carneiro, 1970: 735). Disupuestas así las cosas, una respuesta obvia e inmediata debió haber sido la protección no solo de los recursos, sino también de los mismos asentamientos.

En la versión originalmente desarrollada por Carneiro (1970), en una región circunscrita por el medio ambiente, una población atacada no tiene otra alternativa que defender sus limitados recursos, especialmente cuando sabe que más allá del valle no hay terrenos cultivables ni agua. Dicha situación, a la que Carneiro denomina circunscrito, habría engendrado la violencia, manifestada en forma de ataques sorpresivos, enfrentamientos personales, captura de prisioneros y su posterior decapitación. El diseño y la distribución de los asentamientos establecidos a inicios del Intermedio Temprano en Acarí reflejan precisamente un escenario de violencia.

\section{DISCUSIÓN Y COMENTARIO FINAL}

Una de las mayores dificultades en la arqueología, en general, es determinar qué evidencias arqueológicas son pruebas tangibles de conflicto (Topic \& Topic, 1987; Milner, 1999; Arkush \& Stanish, 2005). Entre otras, esta dificultad surge porque el conflicto puede tomar distintas formas, ocasionando a su vez resultados diversos. Por ejemplo, Allen \& Arkush (2006: 5) ofrecen referencias a asaltos, sabotajes y batallas organizadas. Distinguir dichas variaciones en base a la evidencia arqueológica no es una tarea fácil. No obstante que los especialistas reconocen que los conflictos varían y que, en muchos casos, dependen de las partes en disputa, muchos prefieren generalizarlo bajo una sola nomenclatura: la guerra (Solomento, 2006: 25). De acuerdo a Ferguson (1984: 5), la guerra es la acción «planeada y organizada» de un grupo dirigida hacia otro.

No es mi intención resolver ese dilema, sino simplemente informar de las dificultades. Para los propósitos de este artículo y en base a lo expuesto en las secciones anteriores, parece más probable que el conflicto en el valle de Acarí fue algo identificable como una «guerra de menor escala» (Elliot, 2005: 299). Previamente, Carmichael (1988: 426-427) ya había sostenido similar posición al discutir el caso particular de las cabezas trofeo. En efecto, de acuerdo a Carmichael, los conflictos que se dieron en la costa sur y que resultaron en la obtención de las cabezas trofeo, tomaron la forma de asaltos sorpresivos. Drusini \& Baraybar (1991) 
coinciden con Carmichael al sostener que la presencia de las cabezas de mujeres, hombres y niños es más consistente con la noción de «guerra de menor escala»o específicamente asaltos.

En contraste a una batalla organizada entre dos grupos - donde los participantes son generalmente una sección específica de la población-, como en el escenario propuesto por Verano (1995), los asaltos sorpresivos dirigidos hacia los asentamientos se traducirían en la captura y posterior sacrificio de toda la población. En una región donde los asaltos sorpresivos ocurren, una respuesta inmediata debió haber sido el establecimiento de sistemas defensivos, incluyendo la fortificación. De este modo, debido a la presencia de asentamientos fortificados y cuerpos decapitados, se puede sostener que era una práctica relativamente común en el valle de Acarí.

Dichos asaltos pudieron haber sido impulsados por el interés de acceder a los recursos de las poblaciones vecinas. Tiempos de crisis, ocasionados por una sequía y una mala cosecha, por ejemplo, podrían haber sido razones suficientes para perpetrar tales incursiones. La muerte de personajes de prestigio podría haber sido un motivo adicional que, nuevamente, producirían ataques sorpresivos en los asentamientos vecinos. Contrario a las lógicas de una guerra - dirigidas a eliminar a una población determinada-, lo que se buscaba eran individuos para ser sacrificados. Considerando la orientación particular de los asaltos, edad y sexo no fueron criterios para seleccionar a las víctimas.

A pesar de la falta de evidencias conclusivas que permitan determinar si las víctimas de la decapitación fueron residentes de Amato o habitantes de algún otro asentamiento vecino, es posible adelantar algunas posibilidades, esperando que sean verificadas. Existe la posibilidad que existiera un conflicto al interior del valle de Acarí y entre los habitantes de varios asentamientos que coexistieron. De acuerdo a Thorpe (2003: 146), la mayoría de los conflictos ocurren entre poblaciones relacionadas que participan en varias formas de interacción, como los matrimonios. Coincidentemente, este parece haber sido el caso concreto del valle de Acarí, donde cada sitio estaba separado de su vecino inmediato por espacios vacíos - se destaca la misma variedad de cerámica en todos los asentamientos del valle-. Dicha ocurrencia sugiere, a su vez, que los conflictos no fueron constantes, sino que también existieron tiempos de paz. Como ya ha sido mencionado, huesos con lesiones soldadas no son comunes, lo que indica que las poblaciones no estaban involucradas en conflictos crónicos.

Otra evidencia que sugiere que el conflicto fue interno y los participantes fueron los residentes de varios asentamientos de Acarí, es la presencia del personaje adulto que no fue decapitado pero sí enterrado en el mismo recinto de los otros cuerpos. Dicho personaje, probablemente un antiguo residente de Amato, había sido enterrado siguiendo los patrones de enterramiento practicados en este valle a inicios del periodo Intermedio Temprano (Valdez, 2005b; 2005c; 2005d; 2006). $\mathrm{Al}$ mismo tiempo, dicho individuo poseía un turbante, un rasgo que parece ser característico de la población masculina del valle de Acarí (Valdez, 2006). Junto a los cuerpos decapitados de $\mathrm{H} 10$ se observaron fragmentos de turbante quemados, lo que indica que la población decapitada pertenecía también al valle de Acarí. 
Entre los cuerpos decapitados se hallaron los restos del personaje adulto que no solo fue tratado de una manera distinta (no fue decapitado), sino que también recibió muchas ofrendas (incluyendo artefactos exóticos), como si se tratara de un personaje prestigioso. Como tal, su muerte requirió no solo ofrendas, sino también el sacrificio humano mediante la decapitación. En consecuencia, todo parece indicar que siguiendo la muerte de tal personaje se organizaron los asaltos y la captura de víctimas. A su vez, la presencia de varias deposiciones de cuerpos decapitados tal vez denota eventos separados que, en última instancia, debieron haber sido parte del ritual mortuorio de grandes personajes, quienes, por su status, recibieron tratamientos especiales. El hallazgo de contextos similares en otros asentamientos de Acarí podría confirmar, en parte, algunas de las ideas consideradas en este artículo.

En resumen, la muerte en el valle de Acarí tomó una vía violenta. La presencia de varios asentamientos contemporáneos dotados de sistemas defensivos, junto a las evidencias provenientes de Amato, indican que los conflictos prevalecieron en el valle de Acarí entre las poblaciones que habitaron los asentamientos del valle; de ahí se desprende la existencia de los muros perimétricos. Dichos enfrentamientos no parecen haber sido crónicos, pues la ocurrencia de la misma variedad de cerámica en todos los sitios sugiere que existieron tiempos de tranquilidad. Sin embargo, cuando la violencia tomó su curso, las relaciones se tornaron agresivas y afectaron la vida de muchas personas.

\section{Agradecimientos}

Los trabajos de investigación arqueológica que se vienen efectuando en el valle de Acarí son realizados con autorización del Instituto Nacional de Cultura (Resolución Directoral Nacional 811/INC). Los permisos fueron cedidos por el entonces Director del Instituto Nacional de Cultura, el Dr. Luis G. Lumbreras. Del mismo modo, mi gratitud para Rosa Mazuelo y su esposo Ángel Iglesias por su hospitalidad y por habernos ofrecido un hogar lejos del nuestro. Mi sincero reconocimiento también para mi esposa Katrina y mis hijos Kai y Kía por el constante apoyo que me brindan. David Garon proporcionó gentilmente la traducción del resumen en francés. Finalmente, mi agradecimiento a los editores del Bulletin IFEA, así como a sus evaluadores, especialmente a Ann Peters y Bruce Owen, por sus comentarios y sugerencias a una versión inicial del manuscrito. 


\section{Referencias citadas}

ALLEN, M. W. \& ARKUSH, E. N., 2006 - Introduction: archaeology and the study of war. In: The Archaeology of Warfare: Prehistories of Raiding and Conquest (E. N. Arkush \& M. W. Allen, eds.): 1-19; Gainesville: University of Florida Press.

ARKUSH, E. N. \& STANISH, C., 2005 - Interpreting Conflict in the Andes: implications for the archaeology of warfare. Current Anthropology, 46: 3-28.

BARAYBAR, J. P., 1987 - Cabezas trofeo Nasca: nuevas evidencias. Gaceta Arqueológica Andina, 15: 6-10; Lima: INDEA.

BROWNE, D. M., SILVERMAN, H. \& GARCIA, R., 1993 - A cache of 48 Nasca trophy heads from Cerro Carapo, Peru. Latin American Antiquity, 4: 274-294.

CARMICHAEL, P. H., 1988 - Nasca Mortuary Customs: Death and Ancient Society on the South Coast of Peru, 587 pp.; Calgary: Department of Archaeology, University of Calgary. Ph. D. Dissertation.

CARMICHAEL, P. H., 1994 - The life from death continuum in Nasca imagery. Andean Past, 4: 81-90.

CARMICHAEL, P. H., 1998 - Nasca ceramics: production and social context. In: Andean Ceramics: Technology, Organization, and Approaches (I. Shimada, ed.): 213-231; Philadelphia: University of Pennsylvania, Museum of Archaeology and Anthropology.

CARNEIRO, R. L., 1970 - A theory of the origins of the state. Science, 169: 733-738.

CHACÓN, R. J. \& DYE, D. H., 2007 - Introduction to human trophy taking: an ancient and widespread practice. In: The Taking and Displaying of human Body Parts as Trophies by Amerindians (R. J. Chacon \& D. H. Dye, eds.): 5-31; New York: Springer Publishing.

COEHLO, V. P., 1972 - Enterramentos de cabecas de cultura Nasca; Universidad de Sao Paulo: Department of Communication and Arts. Ph. D. Dissertation.

CONLEE, C. A., 2007 - Decapitation and Rebirth: a headless burial from Nasca, Peru. Current Anthropology, 48 (3): 438-445.

CONLEE, C. A. \& SCHREIBER, K. J., 2006 - The role of intermediate elites in the Balkanization and reformation of Post-Wari society in Nasca, Peru. In: Intermediate Elites in PreColumbian States and Empires (C. M. Elson \& R. A. Covey, eds.): 94-111; Tucson: The University of Arizona Press.

DE LEONARDIS, L., 2000 - The body context: interpreting early Nasca decapitated burials. Latin American Antiquity, 11 (4): 363-386.

DRUSINI, A. G. \& BARAYBAR, J. P., 1991 - Anthropological study of Nasca trophy heads. Homo, 41: 251-265.

ELLIOT, M., 2005 - Evaluating evidence for warfare and environmental stress in settlement pattern data from the Malpaso Valley, Zacatecas, Mexico. Journal of Anthropological Archaeology, 24: 297-315.

FERGUSON, R. B., 1984 - Introduction: Studying War. In: Warfare, Culture, and Environment (R. B. Ferguson, ed.): 1-81; Orlando: Academic Press.

FINUCANE, B. C., 2007 - Trophy heads from Nawinpukio, Peru: physical and chemical analysis of Huarpa-era modified human remains. American Journal of Physical Anthropology, 134 (4):1-10.

FLANNERY, K. V. \& MARCUS, J., 2003 - The origin of war: new 14C dates from ancient Mexico. Proceedings of the National Academy of Sciences of the United States of America, 100 (20): 11801-11805. 
FORGEY, K. \& WILLIAMS, S. R., 2003 - Cabezas trofeo Nasca: evidencias osteológicas y arqueológicas de la colección Kroeber. Revista Andina, 36: 237-261.

FORGEY, K. \& WILLIAMS, S. R., 2005 - Were Nasca trophy heads war trophies or revered ancestors? In: Interacting with the Dead: Perspectives on Mortuary Archaeology for the New Millennium (G. F. M. Rakita, J. E. Buikstra, L. A. Beck \& S. R. Williams, eds.): 251-276; Gainesville: University Press of Florida.

ISLA, J. \& REINDEL, M., 2006 - Burial patterns and sociopolitical organization in Nasca 5 society. In: Andean Archaeology III: North and South (W. H. Isbell \& H. Silverman, eds.): 374-400; New York: Springer Publishing.

KEELEY, L. H., FONTANA, M. \& QUICK, R., 2007 - Baffles and bastions: the universal features of fortifications. Journal of Archaeological Research, 15: 55-95.

KOWTA, M., 1987 - An Introduction to the Archaeology of the Acari Valley in the south coast region of Peru, 95 pp.; Sacramento: California Institute for Peruvian Studies.

KROEBER, A. L., 1956 - Toward definition of the Nazca style. University of California Publications in American Archaeology and Ethnology, 43 (4): 327-432; Berkeley: University of California Press.

LEBLANC, S. A., 1999 - Prehistoric Warfare in the American Southwest, 400 pp.; Salt Lake City: University of Utah Press.

LOTHROP, S. K. \& MAHLER, J., 1957 - Late Nazca Burials at Chaviña, Peru; Cambridge: Harvard University Press. Papers of the Peabody Museum of Archaeology and Ethnology 50 (1).

MILNER, G. R., 1995 - An Osteological perspective on prehistoric warfare. In: Regional Approaches to Mortuary Analysis (L. A. Beck, ed.): 221- 244; New York: Plenum Press.

MILNER, G. R., 1999 - Warfare in prehistoric and early historic eastern North American. Journal of Archaeological Anthropology, 7 (2): 105-151.

MENZEL, D. \& RIDDELL, F. A., 1986 - Archaeological Investigations at Tambo Viejo, Acari Valley, Peru 1954, 123 pp.; Sacramento: California Institute for Peruvian Studies.

NEIRA AVENDAÑO, M. \& COELHO, V. P., 1972-1973 - Enterramientos de cabezas de la cultura Nasca. Revista do Museo Paulista, 20: 109-1142.

PARKINSON, W. A. \& DUFFY, P. R., 2007 - Fortifications and enclosures in European prehistory: a cross cultural perspective. Journal of Archaeological Research, 15: 97-141.

PROULX, D. A., 1968 - Local Differences and Time Differences in Nasca Pottery, 180 pp.; Berkeley: University of California Press. University of California Publications in Anthropology n. 5.

PROULX, D. A., 1971 - Headhunting in Ancient Peru. Archaeology, 24 (1): 16-21.

PROULX, D. A., 1989 - Nasca trophy heads: victims of warfare or ritual sacrifice? In: Cultures in Conflict: Current Archaeological Perspectives (D. C. Tkaczuk \& B. C. Vivian, eds.): 73-85; Calgary: Archaeological Association of the University of Calgary.

PROULX, D. A., 2001 - Ritual uses of trophy heads in ancient Nasca society. In: Ritual Sacrifice in Ancient Peru (E. Benson \& A. Cook, eds.): 119-136; Austin: University of Texas Press.

ROWE, J. H., 1963 - Urban settlements in ancient Peru. Nawpa Pacha, 1: 1-27; Berkeley: Institute of Andean Studies.

SAWYER, A. R., 1961 - Paracas and Nazca iconography. In: Essays in Pre-Columbian Art and Archaeology (S. K. Lothrop, ed.): 269-298; Cambridge: Harvard University Press.

SILVERMAN, H., 1988 - De la historia antigua del Perú: la obtención de las cabezas trofeo. Boletín de Lima, 58: 49-56. 
SILVERMAN, H., 1996 - The Formative Period on the south coast of Peru: a critical review. Journal of World Prehistory, 10 (2): 95-147.

SILVERMAN, H., 2002 - Ancient Nasca Settlement and Society, 224 pp.; lowa City: University of lowa Press.

SILVERMAN, H. \& PROULX, D. A., 2002 - The Nasca, 339 pp.; Malden: Blackwell Publishers.

SOLOMENTO, J., 2006 - The dimensions of war: conflict and culture change in central Arizona. In: The Archaeology of Warfare: Prehistories of Raiding and Conquest (E. N. Arkush \& M. W. Allen, eds.): 23-65; Gainesville: University of Florida Press.

THORPE, I. J. N., 2003 - Anthropology, archaeology, and the origins of warfare. World Archaeology 35 (1): 145-165.

TOPIC, J. R. \& TOPIC, T. L., 1987 - The archaeological study of Andean militarism: some cautionary observations. In: The Origins and Development of the Andean State (J. Haas, S. Pozorski \& T. Pozorski, eds.): 47-55; Cambridge: Cambridge University Press.

VALDEZ, L. M., 1998 - The Nasca and the Valley of Acari: Cultural Interaction on the Peruvian South Coast during the first four Centuries AD, 248 pp.; Calgary: Department of Archaeology, University of Calgary. Ph. D. Dissertation.

VALDEZ, L. M., 2000 - La tradición Huarato de Acarí y sus relaciones con Nasca. Arqueología y Sociedad, 13: 159-171.

VALDEZ, L. M., 2005a - A bird-bone necklace from Amato, Acari Valley, Peru. Canadian Zooarchaeology, 23: 3-9.

VALDEZ, L. M., 2005b - Patrones funerarios del Periodo Intermedio Temprano del Valle de Acarí. Corriente Arqueológica, 1: 43-60.

VALDEZ, L. M., 2005c - Early Intermediate Period mortuary practices in the Acari Valley, Peru; Berkeley: University of California. Ponencia presentada al $45^{\text {th }}$ Annual Meeting of the Institute of Andean Studies, enero 7-8.

VALDEZ, L. M., 2005d - Resting places in antiquity: the case of the Acari Valley, Peru, during the Early Intermediate Period; Calgary: University of Calgary. Ponencia presentada al 38 ${ }^{\text {th }}$ Annual Chacmool Archaeological Conference, noviembre 10-13.

VALDEZ, L. M., 2006 - Los vecinos de Nasca: entierros de la tradición Huarato del valle de Acarí, Perú. Bulletin de I'Institut Français d'Études Andines, 35 (1): 1-20.

VALDEZ, L. M., 2007 - Environmental risk and population pressure: conflict over food and resources in the Acari Valley, Peru; Calgary: University of Calgary. Ponencia presentada al 40 $0^{\text {th }}$ Annual Chacmool Archaeological Conference, noviembre 10-12.

VALDEZ, L. M., BAKER, K. N., RAE C. A. \& GUSTAFSSON, E. C. 2006 - A two thousand year-old mass human sacrifice at Amato, Acari Valley, Peru; Berkeley: University of California. Ponencia presentada al $46^{\text {th }}$ Annual Meeting of the Institute of Andean Studies, enero 6-7.

VAUGHN, K. J. 2005 - Craft and the materialization of chiefly power in Nasca. In: The Foundation of Power in the Prehispanic Andes (K. J. Vaughn, D. E. Ogburn, \& C. A. Conlee, eds.): 113-130; Washingon, D.C.: Archaeological Papers of the American Anthropological Association.

VERANO, J. W. 1995 - Where do they rest? The treatment of human offerings and trophies in ancient Peru. In: Tombs for the Living: Andean Mortuary Practices (T. D. Dillehay, ed.): 189-227; Washington, D.C.: Dumbarton Oaks Research Library. 
VERANO, J. W., 2001 - The physical evidence of human sacrifice in ancient Peru. In: Ritual Sacrifice in Ancient Peru (E. Benson \& A. Cook, eds.): 165-184; Austin: University of Texas Press.

VERANO, J. W., 2003 - Mummified trophy heads from Peru: diagnostic features and medicolegal significance. Journal of Forensic Sciences, 48 (3): 525-530.

WILLIAMS, S. R., FORGEY, K. \& KLASRICH, E. 2001 - An Osteological Study of the Nasca Trophy Heads Collected by A. L. Kroeber during the Marshall Field Expeditions to Peru (1925-1926), 137 pp.; Chicago: Field Museum of Natural History. Fieldiana Anthropology Series 33. 